\title{
Influence of Geographical Location on the Metabolic Production of Giant Barrel Sponges (Xestospongia spp.) Revealed by Metabolomics Tools
}

Lina M. Bayona, Gemma van Leeuwen, Özlem Erol, Thomas Swierts, Esther van der Ent, Nicole J. de Voogd, and Young Hae Choi*

Cite This: ACS Omega 2020, 5, 12398-12408

Read Online

ACCESS | Lلll Metrics \& More | 回 Article Recommendations

Supporting Information

ABSTRACT: Despite their high therapeutic potential, only a limited number of approved drugs originate from marine natural products. A possible reason for this is their broad metabolic variability related to the environment, which can cause reproducibility issues. Consequently, a further understanding of environmental factors influencing the production of metabolites is required. Giant barrel sponges, Xestospongia spp., are a source of many new compounds and are found in a broad geographical range. In this study, the relationship between the metabolome and the geographical location of sponges within the genus Xestospongia spp. was investigated. One hundred and thirty-nine specimens of giant barrel sponges (Xestospongia spp.) collected in four locations, Martinique, Curaçao, Taiwan, and Tanzania, were studied using a multiplatform metabolomics methodology (nuclear magnetic resonance spectroscopy and liquid

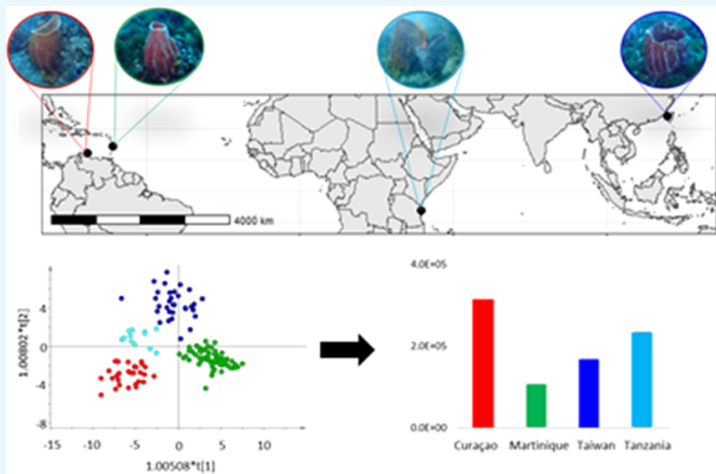
chromatography-mass spectrometry). A clear grouping of the collected samples according to their location was shown. Metabolomics analysis revealed that sterols and various fatty acids, including polyoxygenated and brominated derivatives, were related to the differences in locations. To explore the relationship between observed metabolic changes and their bioactivity, antibacterial activity was assessed against Escherichia coli and Staphylococcus aureus. The activity was found to correlate with brominated fatty acids. These were isolated and identified as (9E,17E)-18-bromooctadeca-9,17-dien-5,7,15-triynoic acid (1), xestospongic acid (2), (7E,13E,15Z)-14,16-dibromohexadeca-7,13,15-trien-5-ynoic acid (3), and two previously unreported compounds.

\section{INTRODUCTION}

Marine natural products (MNP) have a wide chemical diversity, covering a broader area in the chemical spectrum compared to their terrestrial counterparts. ${ }^{1}$ The chemical structures of metabolites isolated from marine organisms contain highly characteristic features and many of them have shown diverse bioactivities. In the past decades, the isolation of novel and bioactive molecules from marine organisms has been a hot issue in natural product research, resulting, so far, in the development of eight drugs, which have been approved and are currently available for the treatment of cancer, HIV, and pain. ${ }^{2-4}$ Despite their potential, the number of approved drugs is low considering the large number of compounds that have been discovered from marine sources. In fact, while more than 1200 new compounds are reported every year, the number of MNP-derived approved drugs has not been increasing at the same rate. ${ }^{1,5,6}$

Although many of the metabolites produced by marine organisms have proved to be active, these compounds are usually produced in very small amounts. ${ }^{7}$ During the process of drug development, large quantities of the compound are required to perform all of the preclinical and clinical trials that are necessary for a drug to be approved. ${ }^{8}$ Unfortunately, the large-scale harvesting of the organism required for this is not feasible either from an economical or an ecological perspective. ${ }^{4}$ Moreover, the production of metabolites in marine organisms can change due to environmental factors such as $\mathrm{pH}$, temperature, predation pressure, and subsequent changes in the symbiont community, making them too unreliable both qualitatively and quantitatively as a natural source of compounds. ${ }^{9}$

To overcome this, diverse approaches have been suggested, including aqua- and mariculture. ${ }^{7,10}$ Although these techniques have not been used yet for the production of compounds at a

Received: March 16, 2020

Accepted: May 7, 2020

Published: May 21, 2020 

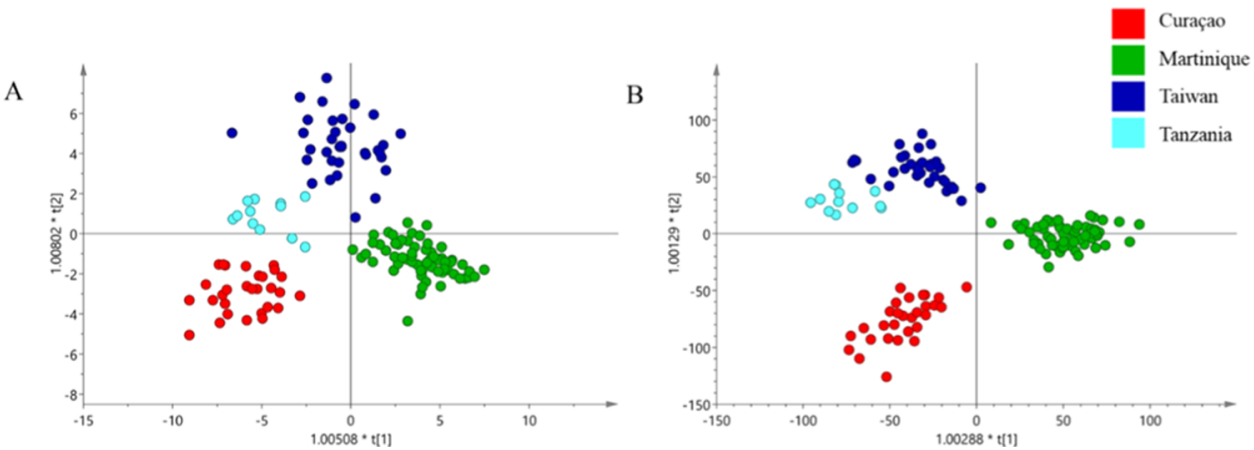

Figure 1. First two components of the OPLS-DA analysis based on ${ }^{1} \mathrm{H}$ NMR (A) and LC-MS (B) of Xestospongia spp. samples collected in four locations: Curaçao (red), Martinique (green), Taiwan (dark blue), and Tanzania (light blue).

commercial scale, it is thought that their implementation could provide sufficient amounts of the compounds to meet the demand for clinical and preclinical trials. ${ }^{11}$ The successful cultivation of marine organisms, mainly of sponges, ${ }^{12-14}$ resulting in the production of higher quantities of active metabolites, ${ }^{15,16}$ could guarantee the reliability of the sources, paving the way for their approval for medicinal use. Optimization of growth and production conditions for the cultivation of the organisms requires an understanding of how biotic and environmental factors affect their metabolome. Such a study involving so many variables can benefit from the use of an untargeted approach that allows the acquisition of the most inclusive picture of the metabolome and then observes how it varies with changing external factors. Metabolomics, defined as comprehensive profiling of all of the metabolites produced by an organism, cell, or tissue at a certain point in time, can provide the information, which could then be used for guidance on a variety of compounds produced and uncovering the factors associated with their production. ${ }^{17}$

Among marine organisms, sponges have been considered to be the most prolific in the production of secondary metabolites, most of which have biological activity as proved by their performance in a wide variety of bioassays. ${ }^{1,7,18}$ In particular, giant barrel sponges, which belong to the genus Xestospongia, have drawn the attention of the scientific community due to their pharmacological activities and their role in ecosystems. ${ }^{19,20}$ In ecological systems, their large size allows them to play an essential role in the reef, providing habitat for other organisms and filtering vast amounts of seawater. $^{21,22}$ Therefore, the tight interaction of giant barrel sponges with their environment makes them an interesting model to study the relationship between metabolites and environmental factors. Also, in some locations, these sponges have been reported to cover up to $9 \%$ of the reef substrate, being more abundant than any other invertebrate. ${ }^{23,24}$ Their chemical composition has been studied, and a wide range of compounds have been isolated including alkaloids, brominated fatty acids, and sterols. Many of these compounds have proved to be bioactive, displaying antibacterial, cytotoxicity, fungicide, and antiretroviral activities. ${ }^{20}$

In addition, giant barrel sponges can be found in a wide geographical range: Xestospongia testudinaria, from the Red Sea to the Indo-Pacific Ocean and Australia, and Xestospongia muta in the tropical regions of the Atlantic Ocean. These two species show very similar genetic and morphological markers. ${ }^{25}$ Furthermore, recent studies revealed the presence of cryptic species in both ocean basins. ${ }^{26}$ Interestingly, for this study, some of the species present in the Caribbean Sea are genetically much closer to species in the Indo-Pacific Ocean than to other species in the same location. ${ }^{26,27}$ These similarities in the cryptic species between locations provide the opportunity to focus on the differences in the metabolome caused by environmental factors.

Geographical location has been identified as one of the most influential factors related to the variation of many sponge metabolites. $^{28-30}$ However, the results that led to this conclusion were aimed at a few target metabolites, while the more general effect on the whole metabolome, which requires a holistic approach, has scarcely been studied. ${ }^{31}$ To study the correlation between the geographical location and metabolic production, 139 specimens of giant barrel sponges (Xestospongia spp.), collected in four different geographic locations, Martinique, Curaçao, Taiwan, and Tanzania, were studied using a holistic approach. Applying the multiplatform metabolomics methodology (nuclear magnetic resonance (NMR) spectroscopy and liquid chromatography-mass spectrometry (LC-MS)), we aimed to investigate the effect of geographical location on the chemical composition of the sponges. Additionally, the correlation between the metabolic changes observed in the samples and their antibacterial activity was evaluated. This proved that the implementation of a metabolomics approach to MNPs can provide relevant information on the conditions required to optimize the production of bioactive compounds. Furthermore, the presence of minor active compounds largely influenced by location-related factors can be revealed using this approach.

\section{RESULTS AND DISCUSSION}

The metabolic profile of giant barrel sponge samples collected in four different geographical locations showed clear differences in the chemical composition of the specimens collected in each location. To compare the general metabolic profile of the samples, ${ }^{1} \mathrm{H}$ NMR and LC-MS were separately applied to the same sample set. This data was further analyzed using an orthogonal partial least-squares discriminant analysis (OPLSDA) model (Figure 1). Both models, ${ }^{1} \mathrm{H}$ NMR and LC-MS, were validated with a $Q^{2}$ value $>0.4$ and cross-validation analysis of variance (CV-ANOVA) test, $p<0.05 .^{32,33}$

In fact, for giant barrel sponges $X$. muta and $X$. testudinaria, the compositions of sterols ${ }^{34}$ and some brominated fatty acids $^{20}$ were previously found to be similar between sponges collected in different oceans. These previous studies showed that despite large geographical separation, giant barrel sponges could share a common metabolic background in qualitative features. In this study, however, a significant separation 
between the samples collected from different places was observed in the OPLS-DA analysis (Figure 1). This result might indicate that the environmental conditions in each location could quantitatively influence the metabolome of the sponges.

The location in which sponges grow involves a number of factors that can influence their development and metabolism, including abiotic factors such as temperature, $\mathrm{pH}$, salinity, or the biotic predatory stress. The effect of the combination of these factors could cause that sponges collected from a specific location produce similar metabolites. Furthermore, Xestospongia spp. are high microbial abundance (HMA) sponges, and microbial communities have been reported to mainly be affected by geographical location. ${ }^{22}$ Thus, it is plausible to find differences in the chemical composition of sponges from different locations, as the metabolome corresponds to the holobiont and the metabolites found can either be produced by the sponge, by the microorganisms, or they can be the product of the interaction of the sponges with microorganisms. ${ }^{2}$

The loading plots of the OPLS-DA analysis (NMR and LCMS data) were analyzed to select the discriminating signals and subsequently identify the corresponding compounds. The characteristic ${ }^{1} \mathrm{H}$ NMR chemical shifts are shown in a heat map in Figure 2, obtained by calculation of the variable importance

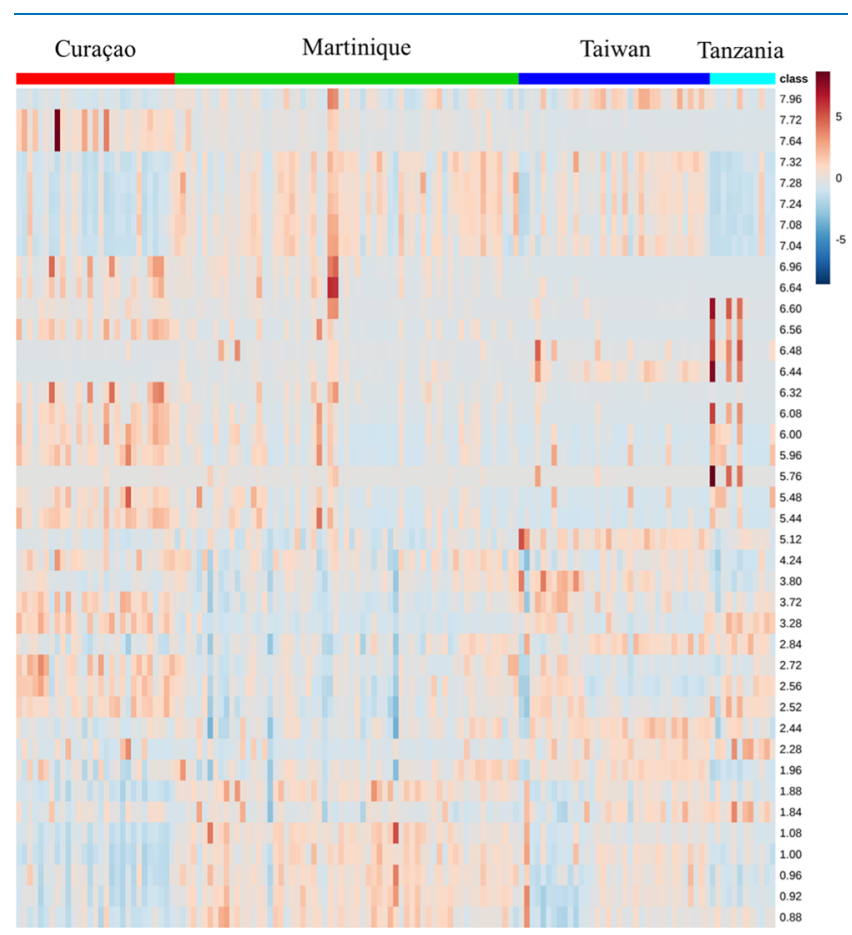

Figure 2. Heat map of characteristic signals from ${ }^{1} \mathrm{H}$ NMR data obtained from the variable importance for the projection (VIP) plot of orthogonal partial least-squares discriminant analysis (OPLS-DA).

for the projection (VIP) values. The signals correlated with the samples from Martinique were found mainly in two regions of the spectra. The region between $\delta_{\mathrm{H}} 0.80$ and 1.00 was assigned to methyl groups in sterols. Particularly the singlets in the range of $\delta_{\mathrm{H}}$ 0.7-0.8 were assigned to methyls $\mathrm{H}-18$ and $\mathrm{H}-19$ in sterols. Many steroids have been reported in Xestospongia spp., including conventional sterols, ${ }^{35}$ and brominated fatty acid esters. ${ }^{36}$ The aromatic region between $\delta_{\mathrm{H}} 7.04$ and $\delta_{\mathrm{H}}$ 7.32 is characteristic of phenolic signals that could correspond to known phenolics of Xestospongia such as quinones, ${ }^{37}$ isoquinoline alkaloids, ${ }^{38}$ and $\beta$-carboline alkaloids. ${ }^{39}$ Samples from Curaçao were distinguished by abundant signals in the range of $\delta_{\mathrm{H}} 2.50-3.80$. Signals downfield of this range $\left(\delta_{\mathrm{H}}\right.$ 3.0-3.8) correspond to protons attached to oxygen-bearing carbons. These could thus be attributed to hydroxylated polyunsaturated fatty acids since there are many reports of the isolation of this class of fatty acids from Xestospongia spp. ${ }^{40-42}$ Taiwan samples displayed characteristic signals between $\delta_{\mathrm{H}}$ 6.40 and 6.60 , which correspond to double bonds commonly occurring in brominated unsaturated fatty acids. Samples from Tanzania had no distinguishing signals in a specific region of the spectrum, indicating that the changes present in this location do not involve a family of compounds but rather specific compounds.

The NMR analysis provided a general overview of the metabolic profiles, allowing the detection of families of compounds predominant in each location. However, the congestion of signals in the spectra and the relatively low sensitivity rendered the identification of individual metabolites unfeasible. Thus, LC-MS/quadrupole time-of-flight (Q-TOF) was used to identify these metabolites, especially the minor ones. As shown in Figure 1b, metabolic differences in the samples from each location were as clear as those observed with ${ }^{1} \mathrm{H}$ NMR. As in the case of ${ }^{1} \mathrm{H}$ NMR, a VIP plot was also used for the identification of peaks responsible for the separation. However, dereplication of the 50 most relevant peaks obtained from the VIP plot was not successful because most of the selected MS features could not be identified or they corresponded to several isomers. Nevertheless, information on a specific metabolite group, brominated fatty acids, was obtained from the MS data. Different types of brominated fatty acids were found as marker features in the samples on each location. The Martinique samples showed no brominecontaining signals, while the Curaçao samples were discriminated by their characteristic dibrominated metabolites and the samples from Taiwan and Tanzania by monobrominated ones.

The variation in the chemical composition of the samples observed in this study proves the plasticity of Xestospongia spp. in terms of their biosynthesis processes. This could partly explain the great diversity in compounds isolated from this same sponge genus all over the world. Considering that these compounds exhibit a wide range of biological activities, it could be presumed that this metabolic differentiation observed in samples from different locations could be reflected in their bioactivity. ${ }^{28}$ To investigate this potential correlation, the antimicrobial activity of Xestospongia spp. extracts against a Gram-positive (S. aureus) and a Gram-negative (E. coli) bacteria was assayed. This particular bioactivity was chosen due to numerous reports of antimicrobial compounds in Xestospongia spp. collected throughout the world. ${ }^{43,44}$

The result of the activity test showed that some sponge extracts were active against $S$. aureus at a concentration of 512 $\mu \mathrm{g} / \mathrm{mL}$. From the whole sample set, $11.5 \%$ of the collected samples displayed activity, although there was a large variation in the activity according to the location. For example, while $20 \%$ of the samples collected in Taiwan had antimicrobial activity, none of the samples from Tanzania displayed activity. This indicates that the ratio of active and nonactive samples was not significantly related to the collection places $\left(\chi^{2}(2)=\right.$ 2.72, $p=0.256)$. The lack of correlation between these two factors suggests that the production of antibacterial compounds is triggered by a factor occurring within a smaller spatial scale or is driven by genetic variation. 
On the other hand, none of the samples showed activity against E. coli, a proteobacteria, when tested at a concentration of $512 \mu \mathrm{g} / \mathrm{mL}$. The lack of activity against E.coli can be explained by the fact that proteobacteria are one of the most predominant phyla among the bacterial communities of Xestospongia spp. ${ }^{2,45}$ Therefore, it is a natural result that they do not produce compounds that could inhibit the growth of these types of bacteria.

To identify the compounds specifically involved in the antibacterial activity against $S$. aureus, an OPLS-DA model was built, grouping the samples as active (showed activity at 512 $\mu \mathrm{g} / \mathrm{mL}$ ) and nonactive (no activity shown at concentrations of $512 \mu \mathrm{g} / \mathrm{mL}$ ) and using both NMR and LC-MS data. The model based on the NMR data was not validated and did not reveal differences between the two groups. In this case, overlapping of signals belonging to compounds of the same family or low sensitivity could explain the lack of validation, as the activity must be related to specific compounds. On the other hand, with the LC-MS data, it was possible to separate the samples that displayed activity from the nonactive samples as shown in Figure 3. Although variation in the chemical

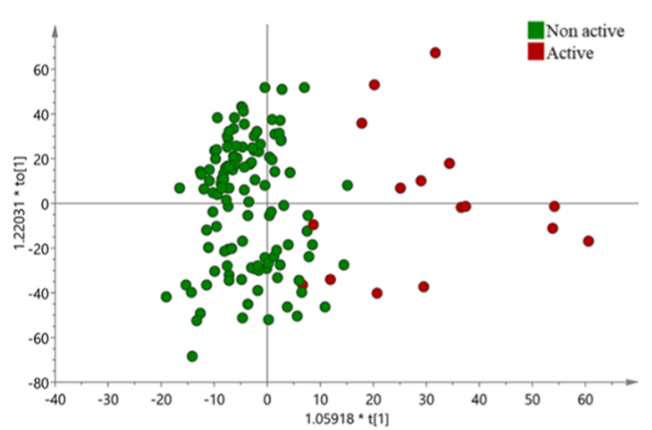

Figure 3. Orthogonal partial least-squares discriminant analysis (OPLS-DA) model for the 139 Xestospongia spp. samples categorized by their activity against $S$. aureus using LC-MS data.

composition among the active samples was observed, a list of the masses of potentially active compounds was made using an S-plot (Supporting Information Table S2). These features, together with the list obtained previously from the OPLS-DA analysis using location as a factor, were used to target the compounds of interest from samples collected in Martinique, Curaçao, and Taiwan. The great dispersion observed between the active samples suggested that although all samples exhibited activity, it was not necessarily due to the same compounds or, alternatively, that there was a significant variation in the number of active compounds present in the samples depending on the location. To clarify this, some of the most active compounds were isolated and tested, and their resulting activity was compared with their occurrence in different locations.

Isolation and Structural Elucidation. Ethanolic extracts of samples from Martinique, Curaçao, and Taiwan that were active against $S$. aureus were prepared to isolate potentially active antimicrobial compounds. These extracts were subjected to fractionation with liquid chromatography using the list of potential active features as a criterion for fraction selection. This led to the isolation of five brominated fatty acid analogues (Figure 4): two from Martinique extracts $(1,2)$, two from Curaçao extracts $(3,4)$, and one from Taiwan extracts $(5)$.<smiles>O=C(O)CCCC#CC#C/C=C/CCCCC#C/C=C/Br</smiles>

(1)<smiles>O=C(O)CCCCCC#C/C=C/CCCC#C/C=C/Br</smiles><smiles>O=C(O)CCC#CC=CCCCCCC=C(Br)C=CBr</smiles>

(3)

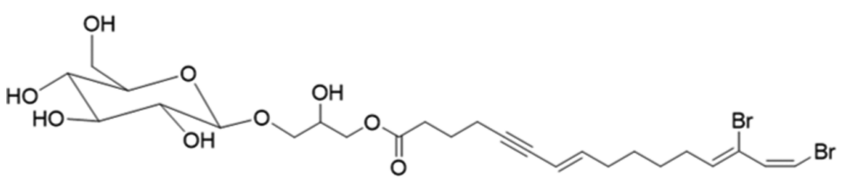

(4)

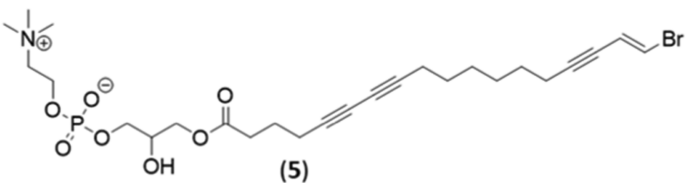

Figure 4. Structure of the compounds isolated from the giant barrel sponge (Xestospongia spp.). (9E,17E)-18-bromooctadeca-9,17-dien5,7,15-triynoic acid (1), xestospongic acid (2), (7E,13E,15Z)-14,16dibromohexadeca-7,13,15-trien-5-ynoic acid (3), compound (4), and compound (5).

Compound $\mathbf{1}$ was isolated from a Martinique sample as a white powder. The (+)-HRESIMS spectrum of 1 showed the proton adduct $[\mathrm{M}+\mathrm{H}]^{+}$ions at $m / z 347.0646$ and 349.0631, with relative intensities of $1: 1$, suggesting the presence of one bromine atom in the molecule. The molecular formula was deduced to be $\mathrm{C}_{18} \mathrm{H}_{19} \mathrm{BrO}_{2}$. The ${ }^{1} \mathrm{H}$ NMR $\left(\mathrm{CH}_{3} \mathrm{OH}-d_{4}, 600\right.$ $\mathrm{MHz}$ ) spectrum (Supporting Information Figure $\mathrm{S} 3$ ) of the compound showed the presence of two double bonds and the ${ }^{13} \mathrm{C} \mathrm{NMR}\left(\mathrm{CH}_{3} \mathrm{OH}-d_{4}, 150 \mathrm{MHz}\right)$ showed one carboxylic acid carbon and the presence of three triple bonds. The molecular formula, together with the characteristic NMR signals, was dereplicated using the Dictionary of Natural Products. The compound was identified as (9E,17E)-18-bromooctadeca-9,17dien-5,7,15-triynoic acid, which had been previously isolated from $X$. muta collected in Columbus Island, Bahamas, and reported to inhibit the HIV-1 protease with an $\mathrm{IC}_{50}$ of $8 \mu \mathrm{M}^{46}$

Compound $\mathbf{2}$ was also isolated from a Martinique sample as a white powder. The (+)-HRESIMS spectrum of 2 showed the proton adduct $[\mathrm{M}+\mathrm{H}]^{+}$ions at $\mathrm{m} / z 351.0956$ and 353.0939, with relative intensities of $1: 1$. This isotopic pattern suggested the presence of a bromine atom in the molecule. The molecular formula was deduced to be $\mathrm{C}_{18} \mathrm{H}_{23} \mathrm{BrO}_{2}$. The ${ }^{1} \mathrm{H}$ NMR $\left(\mathrm{CH}_{3} \mathrm{OH}-d_{4}, 600 \mathrm{MHz}\right)$ spectroscopic data (Supporting Information Figure $\mathrm{S} 7$ ) showed the presence of two double bonds and ${ }^{13} \mathrm{C}$ NMR $\left(\mathrm{CH}_{3} \mathrm{OH}-d_{4}, 150 \mathrm{MHz}\right)$ showed the presence of two triple bonds. A search using the molecular formula and the characteristic NMR signals in the Dictionary of Natural Products yielded the compound (9E,17E)-18bromooctadeca-9,17-dien-7,15-diynoic acid, also known as 
xestospongic acid. This compound had been originally isolated from Xestospongia sp. samples collected in Australia as one of the most abundant compounds in the sample, accounting for $0.1 \%$ of the dry weight material. ${ }^{47}$

Compound $\mathbf{3}$ was isolated from a Curaçao sample as a white powder. Its $(+)$-HRESIMS spectrum showed the proton and sodium adduct $[\mathrm{M}+\mathrm{H}]^{+}$and $[\mathrm{M}+\mathrm{Na}]^{+}$ions at $\mathrm{m} / z$ 402.9904, 404.9884, and 406.9867, and 424.9727, 426.9706, and 428.9685 , respectively, both having a relative intensity of $1: 2: 1$. This isotopic pattern indicates the presence of two bromine atoms in the molecule. The molecular formula was deduced to be $\mathrm{C}_{16} \mathrm{H}_{20} \mathrm{Br}_{2} \mathrm{O}_{2} .{ }^{1} \mathrm{H}$ NMR $\left(\mathrm{CH}_{3} \mathrm{OH}-d_{4}, 600\right.$ $\mathrm{MHz}$ ) spectroscopic data (Supporting Information Figure S11) showed the presence of three double bonds in the molecule and the ${ }^{13} \mathrm{C}$ NMR $\left(\mathrm{CH}_{3} \mathrm{OH}-d_{4}, 150 \mathrm{MHz}\right)$ showed one carboxylic acid carbon and one triple bond. The molecular weight together with the NMR signal in the Dictionary of Natural Products led to the identification of the compound as (7E,13E,15Z)-14,16-dibromohexadeca-7,13,15-trien-5-ynoic acid. This compound had been previously reported from $X$. muta collected in Summerland Key, Florida, and in Portobelo Bay, Panamá. ${ }^{48,49}$

Compound 4 was also isolated from a Curaçao sample as a white powder. Its $(+)$-HRESIMS spectrum showed the proton and sodium adducts $[\mathrm{M}+\mathrm{H}]^{+}$and $[\mathrm{M}+\mathrm{Na}]^{+}$ions at $\mathrm{m} / z$ 639.0777, 641.0761, and 643.0749 and 661.0580, 663.0581, and 665.0563 , respectively, both sets of ions with a relative intensity of $1: 2: 1$. This isotopic pattern indicates the presence of two bromine atoms in the molecule. The molecular formula was deduced to be $\mathrm{C}_{25} \mathrm{H}_{36} \mathrm{Br}_{2} \mathrm{O}_{9}$, which requires 7 degrees of unsaturation. The ${ }^{1} \mathrm{H}$ NMR and ${ }^{13} \mathrm{C}$ NMR spectroscopic data (Table 1) and heteronuclear single quantum correlation (HSQC) spectrum revealed 10 methylene $\left(\delta_{\mathrm{H}} / \delta_{\mathrm{C}} 1.40 / 29.5\right.$, $1.44 / 29.1,1.82 / 25.2,2.04 / 32.0,2.08 / 33.6,2.35 / 19.4,2.48 /$ 33.8, 3.67-3.87/62.7, 3.92-3.66/71.9 4.17/66.7), six methine $\left(\delta_{\mathrm{H}} / \delta_{\mathrm{C}} 3.21 / 75.1,3.28 / 78.0,3.29 / 71.6,3.36 / 77.9,4.00 / 69.6\right.$, $4.28 / 104.7)$, and five olefinic protons $\left(\delta_{\mathrm{H}} / \delta_{\mathrm{C}} 5.45 / 111.3\right.$, $5.99 / 144.0,6.07 / 137.4,6.56 / 113.4,6.78 / 132.3)$. The signal at $104.7 \mathrm{ppm}$ is very characteristic for a carbon atom joined to two oxygen atoms, which indicates the presence of a sugar moiety in the molecule. In addition, the ${ }^{13} \mathrm{C}$ NMR spectrum showed four nonprotonated carbons, consisting of one ester carbonyl $\left(\delta_{\mathrm{C}} 174.9\right)$, two sp carbons $\left(\delta_{\mathrm{C}} 80.9,88.1\right)$, and one olefinic carbon $\left(\delta_{\mathrm{C}} 114.8\right)$. The presence of aliphatic signals together with a carbonyl and $\mathrm{sp}$ and $\mathrm{sp}^{2}$ carbons indicates that the structure contains an unsaturated fatty acid moiety. Two of the olefinic carbons are shifted upfield, indicating the presence of a substituent that increases the protection over those carbons. This is in agreement with the presence of two bromine atoms observed in the mass spectra and with the lack of any terminal methyl or methylene groups. It was thus possible to establish the attachment of bromine atoms to terminal olefinic carbons at $\delta_{\mathrm{c}} 114.8$ and $\delta_{\mathrm{c}} 113.4$.

Further examination of $\mathrm{HMBC}$ and COSY correlations allowed us to establish the full structure of compound 4 (Figure 5) as consisting of three moieties: a dibrominated unsaturated fatty acid, a glycerol molecule, and a sugar moiety. The brominated fatty acid and the sugar are attached to $\mathrm{C} 1$ and $\mathrm{C} 3$ of the glycerol molecule, respectively. The chemical shift of $\delta_{\mathrm{c}} 104.7$ was assigned to the anomeric carbon of the sugar, which is attached to C3 of the glycerol moiety through a glycosidic bond. Additionally, NOESY showed correlations between the anomeric proton and those in positions 3 " and 5".
Table 1. NMR Spectroscopic Data for Compounds 4 and $5^{a}$

\begin{tabular}{|c|c|c|c|c|}
\hline \multirow[b]{2}{*}{ position } & \multicolumn{2}{|c|}{ compound 4} & \multicolumn{2}{|r|}{ compound 5} \\
\hline & $\begin{array}{l}{ }^{13} \mathrm{C} \text { NMR } \\
\delta \text {, type }\end{array}$ & $\begin{array}{c}{ }^{1} \mathrm{H} \text { NMR } \delta,(J \\
\text { in } \mathrm{Hz})\end{array}$ & $\begin{array}{l}{ }^{13} \mathrm{C} \text { NMR } \\
\delta \text {, type }\end{array}$ & ${ }^{1} \mathrm{H}$ NMR $\delta$, $(J$ in $\mathrm{Hz})$ \\
\hline $1^{\prime}$ & 174.9, C & & 174.6, C & \\
\hline $2^{\prime}$ & $\begin{array}{l}33.8 \\
\mathrm{CH}_{2}\end{array}$ & $2.48 \mathrm{t}(7.3)$ & $\begin{array}{l}33.7 \\
\mathrm{CH}_{2}\end{array}$ & $2.49 \mathrm{t}(7.6)$ \\
\hline $3^{\prime}$ & $\stackrel{25.2,}{\mathrm{CH}_{2}}$ & $1.82 \mathrm{~m}$ & $\stackrel{24.8}{\mathrm{CH}_{2}}$ & 1.83 quint $(7.2)$ \\
\hline $4^{\prime}$ & $\begin{array}{l}19.4 \\
\mathrm{CH}_{2}\end{array}$ & $\begin{array}{l}2.35 \mathrm{td}(7.0, \\
1.8)\end{array}$ & $\begin{array}{l}19.2 \\
\mathrm{CH}_{2}\end{array}$ & $2.35 \mathrm{t}(7.0)$ \\
\hline $5^{\prime}$ & $88.1, \mathrm{C}$ & & 76.8, C & \\
\hline $6^{\prime}$ & $80.9, \mathrm{C}$ & & 66.3, C & \\
\hline $7^{\prime}$ & $\begin{array}{r}111.3 \\
\mathrm{CH}\end{array}$ & $5.45 \mathrm{dm}(15.8)$ & 66.3, C & \\
\hline $8^{\prime}$ & $\begin{array}{c}144.0 \\
\mathrm{CH}\end{array}$ & $\begin{array}{l}5.99 \mathrm{dt}(15.8, \\
7.1)\end{array}$ & $78.2, C^{b}$ & \\
\hline $9^{\prime}$ & $\begin{array}{l}33.6 \\
\mathrm{CH}_{2}\end{array}$ & $2.08 \mathrm{~m}$ & $\begin{array}{l}\text { 19.6, } \\
\mathrm{CH}_{2}\end{array}$ & $2.28 \mathrm{~m}$ \\
\hline $10^{\prime}$ & $\begin{array}{l}29.5 \\
\mathrm{CH}_{2}\end{array}$ & $1.40 \mathrm{~m}$ & $\begin{array}{l}29.3 \\
\mathrm{CH}_{2}\end{array}$ & $1.43 \mathrm{~m}$ \\
\hline $11^{\prime}$ & $\begin{array}{l}29.1 \\
\mathrm{CH}_{2}\end{array}$ & $1.44 \mathrm{~m}$ & $\begin{array}{l}29.3 \\
\mathrm{CH}_{2}\end{array}$ & $1.54 \mathrm{~m}$ \\
\hline $12^{\prime}$ & $\begin{array}{l}32.0 \\
\mathrm{CH}_{2}\end{array}$ & $2.04 \mathrm{~m}$ & $\begin{array}{l}29.3 \\
\mathrm{CH}_{2}\end{array}$ & $1.54 \mathrm{~m}$ \\
\hline $13^{\prime}$ & $\begin{array}{c}137.4 \\
\mathrm{CH}\end{array}$ & $\begin{array}{l}6.07 \mathrm{td}(7.7, \\
1.5)\end{array}$ & $\begin{array}{l}29.4 \\
\mathrm{CH}_{2}\end{array}$ & $1.43 \mathrm{~m}$ \\
\hline $14^{\prime}$ & $114.8, \mathrm{C}$ & & $\begin{array}{l}19.9 \\
\mathrm{CH}_{2}\end{array}$ & $2.30 \mathrm{~m}$ \\
\hline $15^{\prime}$ & $\begin{array}{r}132.3 \\
\mathrm{CH}\end{array}$ & $6.78 \mathrm{dm}(7.6)$ & $78.3, C^{b}$ & \\
\hline $16^{\prime}$ & $\begin{array}{r}113.4 \\
\mathrm{CH}\end{array}$ & $6.56 \mathrm{~d}(7.6)$ & 93.8, C & \\
\hline $17^{\prime}$ & & & $\begin{array}{r}119.2 \\
\mathrm{CH}\end{array}$ & $6.24 \mathrm{dt}(14.0,2.3)$ \\
\hline $18^{\prime}$ & & & $\begin{array}{r}117.9 \\
\mathrm{CH}\end{array}$ & $6.70 \mathrm{~d}(14.0)$ \\
\hline 1 & $\begin{array}{l}66.7 \\
\mathrm{CH}_{2}\end{array}$ & $4.17 \mathrm{~m}$ & $\begin{array}{l}67.8 \\
\mathrm{CH}_{2}\end{array}$ & $3.92 \mathrm{~m}$ \\
\hline 2 & 69.6, CH & $4.00 \mathrm{~m}$ & $69.8, \mathrm{CH}$ & $3.99 \mathrm{~m}$ \\
\hline 3 & $\begin{array}{l}71.9 \\
\mathrm{CH}_{2}\end{array}$ & $\begin{array}{l}3.92 \mathrm{dd}(10.5 \\
5.2), 3.66 \mathrm{~m}\end{array}$ & $\begin{array}{l}66.3 \\
\mathrm{CH}_{2}\end{array}$ & $\begin{array}{l}4.21 \mathrm{dd}(11.4,4.5) \\
\quad 4.14 \mathrm{dd}(11.4,6.2)\end{array}$ \\
\hline $1^{\prime \prime}$ & $\begin{array}{r}\text { 104.7, } \\
\text { CH }\end{array}$ & $4.28 \mathrm{~d}(7.8)$ & $\begin{array}{l}67.0 \\
\mathrm{CH}_{2}\end{array}$ & $3.66 \mathrm{~m}$ \\
\hline $2^{\prime \prime}$ & 75.1, CH & $3.21 \mathrm{~m}$ & $\begin{array}{l}\text { 60.4, } \\
\mathrm{CH}_{2}\end{array}$ & $4.31 \mathrm{~m}$ \\
\hline $3^{\prime \prime}$ & 77.9, $\mathrm{CH}$ & $3.36 \mathrm{bs}$ & & \\
\hline $4^{\prime \prime}$ & 71.6, $\mathrm{CH}$ & $3.29 \mathrm{~m}$ & & \\
\hline $5^{\prime \prime}$ & 78.0, $\mathrm{CH}$ & $3.28 \mathrm{bs}$ & & \\
\hline $6^{\prime \prime}$ & $\begin{array}{l}\text { 62.7, } \\
\mathrm{CH}_{2}\end{array}$ & $\begin{array}{c}3.87 \mathrm{dd}(12.1 \\
1.8), 3.67 \mathrm{~m}\end{array}$ & & \\
\hline $\mathrm{N}-\mathrm{Me}$ & & & $\begin{array}{l}54.7 \\
\mathrm{CH}_{3}\end{array}$ & $3.24 \mathrm{~s}$ \\
\hline
\end{tabular}

${ }^{a}$ NMR spectra were recorded in $\mathrm{CH}_{3} \mathrm{OH}-d_{4},{ }^{1} \mathrm{H} 600 \mathrm{MHz}$, and ${ }^{13} \mathrm{C}$ $150 \mathrm{MHz} .{ }^{b}$ These carbons are interchangeable.

This correlation, together with the coupling constants of the anomeric proton $(J=7.8 \mathrm{~Hz})$ and protons $3^{\prime \prime}$ and $4^{\prime \prime}(J>8$ $\mathrm{Hz}$ ) obtained from $J$-Resolved spectra, allowed the identification of the sugar moiety as $\beta$-glucose. This was also supported by reported ${ }^{13} \mathrm{C}$ NMR chemical shifts of the $\beta$ glucose moiety in similar compounds. ${ }^{50,51}$ The identical chemical shift and coupling constant of $\mathrm{H}-13^{\prime}$ indicated that the double bond in position 13' would have the same configuration as that of compound 3. Lastly, the double bond in position $7^{\prime}$ was confirmed to have an $E$ configuration with its characteristic coupling constant $(J=15.8 \mathrm{~Hz})$, while the 


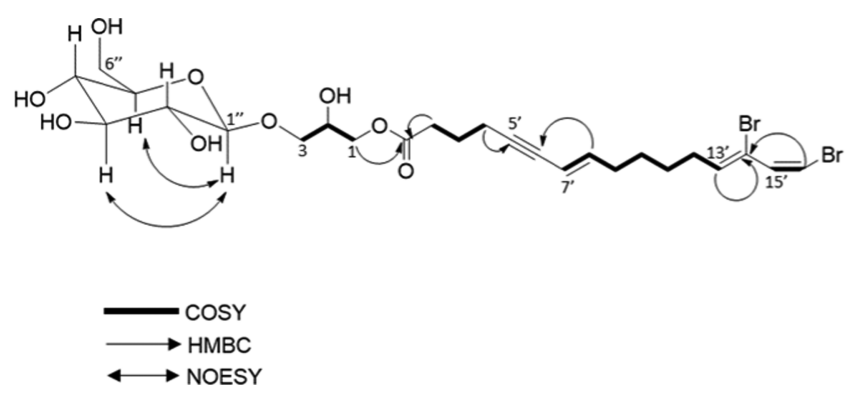

Figure 5. Important COSY, HMBC, and NOE correlations of compound 4.

terminal double bond was found to have a $Z$ configuration with the coupling constant $(J=7.6 \mathrm{~Hz})^{48,49}$

Compound $\mathbf{5}$ was isolated from a sample from Taiwan as a white powder. The (+)-HRESIMS spectrum of $\mathbf{5}$ showed the proton adduct $[\mathrm{M}+\mathrm{H}]^{+}$ions at $m / z 588.1718$ and 590.1702 . The ions have a relative intensity of $1: 1$, indicating the presence of a bromine atom in the molecule. The molecular formula was deduced to be $\mathrm{C}_{26} \mathrm{H}_{39} \mathrm{BrNO}_{7} \mathrm{P}$. The ${ }^{1} \mathrm{H}$ NMR and ATP ${ }^{13} \mathrm{C}$ NMR spectroscopic data (Table 1) and HSQC correlation revealed the presence of three overlapping methyl groups joined to a nitrogen atom $\left(\delta_{\mathrm{H}} / \delta_{\mathrm{C}} 3.24 / 54.7 \times 3\right), 13$ methylene $\left(\delta_{\mathrm{H}} / \delta_{\mathrm{C}} 1.43 / 29.4,1.43 / 29.3,1.54 / 29.3 \times 2,1.83 /\right.$ $24.8,2.28 / 19.6,2.30 / 19.9,2.35 / 19.2,2.49 / 33.7,3.66 / 67.0$, $3.92 / 67.8,4.14-4.21 / 66.3,4.31 / 60.4)$, one methyne $\left(\delta_{\mathrm{H}} / \delta_{\mathrm{C}}\right.$ $3.99 / 69.8)$, two olefinic protons $\left(\delta_{\mathrm{H}} / \delta_{\mathrm{C}} 6.24 / 119.2,6.70 /\right.$ $117.9)$, and seven carbons with no protons attached, consisting of one carbonyl ester $\left(\delta_{\mathrm{C}} 174.6\right)$ and six sp carbons $\left(\delta_{\mathrm{C}} 66.3 \times\right.$ $2,76.8,78.2,78.3,93.8)$. The sp carbons indicate the presence of three triple bonds in the molecule. However, some of the $\delta_{\mathrm{C}}$ are shifted downfield, suggesting that two of the triple bonds are conjugated. As for compound 5, the lack of a terminal methyl or methylene along with the low chemical shift of the olefinic carbon indicates the presence of a terminal olefinic bond attached to a bromine atom. Further examination of $\mathrm{HMBC}$ and COSY correlations established the structure of $\mathbf{5}$ (Figure 6) as consisting of three moieties: a brominated fatty

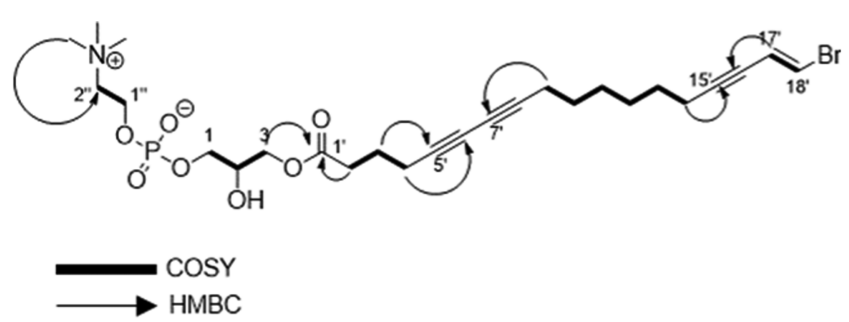

Figure 6. COSY and HMBC important correlations of compound 5.

acid, a molecule of glycerol, and a molecule of phosphatidylcholine. The presence of a phosphate group can be deduced from analysis of the exact mass of the molecule.

All of the isolated compounds contained one or more triple bonds in their structures; thus, they are classified as polyacetylenes. These kinds of compounds have been reported in a wide range of marine organisms such as algae, corals, mollusks, and sponges. In the case of sponges, the genera Petrosia, Callyspongia, and Xestospongia are the main sources of polyacetylene compounds, and, in some cases, they have even been considered to be a chemotaxonomic marker of these genera. ${ }^{52}$ Although the biosynthetic pathway and ecological function of these kinds of compounds are still unclear, they have shown a wide range of biological activities. In this study, all of the isolated compounds exhibited mild activity against $S$. aureus (1: $64 \mu \mathrm{g} / \mathrm{mL}, 2: 256 \mu \mathrm{g} / \mathrm{mL}, 3: 64 \mu \mathrm{g} / \mathrm{mL}, 4: 64 \mu \mathrm{g} /$ $\mathrm{mL}$, 5: $128 \mu \mathrm{g} / \mathrm{mL})$. Thus, the inconsistency in the relationship between the activity and location in which the sponges were collected can be explained by the fact that the compounds responsible for the activity might differ in their concentration or their structure in each location.

A comparison of the occurrence of the isolated compounds between the locations showed different patterns for each compound (Figure 7). Interestingly, compound 2, isolated from a sample collected in Martinique, was more abundant in samples from the other three locations. This compound has been previously isolated from Xestospongia spp. samples collected in Australia, ${ }^{47}$ the Red Sea, ${ }^{53}$ and Mayotte on the coast of Africa. ${ }^{44}$ The occurrence of 2 in Xestospongia spp. samples collected all over the world indicates that although it is a constitutive metabolite of sponges of the genus Xestospongia, the environmental factors prevalent in each location may affect the amount in which this metabolite is produced.

Compounds 3 and $\mathbf{4}$ were more abundant in samples from the Caribbean region, mainly Curaçao. Both compounds have two atoms of bromine in their structures that distinguish them from the other compounds isolated in this study. Compound $\mathbf{4}$ as such has not been previously reported, but its fatty acid moiety corresponds to compound 3 . Moreover, compound 3 has been previously isolated from a sample collected in Florida ${ }^{48}$ and Pánama. ${ }^{49}$ Since these compounds occur mainly in the Caribbean region, they might be used to distinguish the sponges from this region. Lastly, compound $\mathbf{5}$ is a phospholipid from the phosphatidylcholine group. These compounds are known to be part of the cellular membrane in animals, having not only structural functions but also playing a role in the signaling of metabolic pathways. ${ }^{54}$ The variability observed in the amount of $\mathbf{5}$, which is more abundant in samples from Taiwan and Tanzania than samples from the Caribbean, suggests that similarly to what occurs in animal cell membranes, this compound also has more than just a structural role in Xestospongia spp. and its production is thus conditioned by the environmental factors related to each location.

\section{EXPERIMENTAL SECTION}

Sample Collection and Extraction. Xestospongia spp. samples were collected in Martinique, Curaçao, Tanzania, and Taiwan, and stored in ethanol at $-20{ }^{\circ} \mathrm{C}$ (Supporting Information Table S1). Samples were transported to the Institute of Biology of Leiden University for further analysis. The Xestospongia samples were ground and extracted with ethanol and sonicated for $20 \mathrm{~min}$. The extraction was done in triplicate. An aliquot of $1 \mathrm{~mL}$ of each extract was dried and used for ${ }^{1} \mathrm{H}$ NMR analysis. The remaining extracts were dried. The salt from the extracts was removed using C-18 SPE Supelco Supelclean LC-18 (Merck, Darmstadt, Germany) cartridges. For each extract, $50 \mathrm{mg}$ were loaded into the cartridge and eluted with solvents of decreasing polarity, i.e., $\mathrm{H}_{2} \mathrm{O}$ (F1), $\mathrm{MeOH}$ (F2), and $\mathrm{MeOH} / \mathrm{DCM}$ (1:1) (F3). The methanol fraction (F2) was used for further LC-MS analysis.

Metabolomic Study. ${ }^{1} \mathrm{H}$ NMR Analysis and Data Preprocessing. The dry extract was resuspended in $1 \mathrm{~mL}$ of deuterated methanol $\left(\mathrm{CH}_{3} \mathrm{OH}-d_{4}\right)$ with hexamethyl disiloxane (HMDSO) as the internal standard. The ${ }^{1} \mathrm{H}$ NMR spectra were measured at $25{ }^{\circ} \mathrm{C}$ in an AV-600 $\mathrm{MHz}$ NMR 


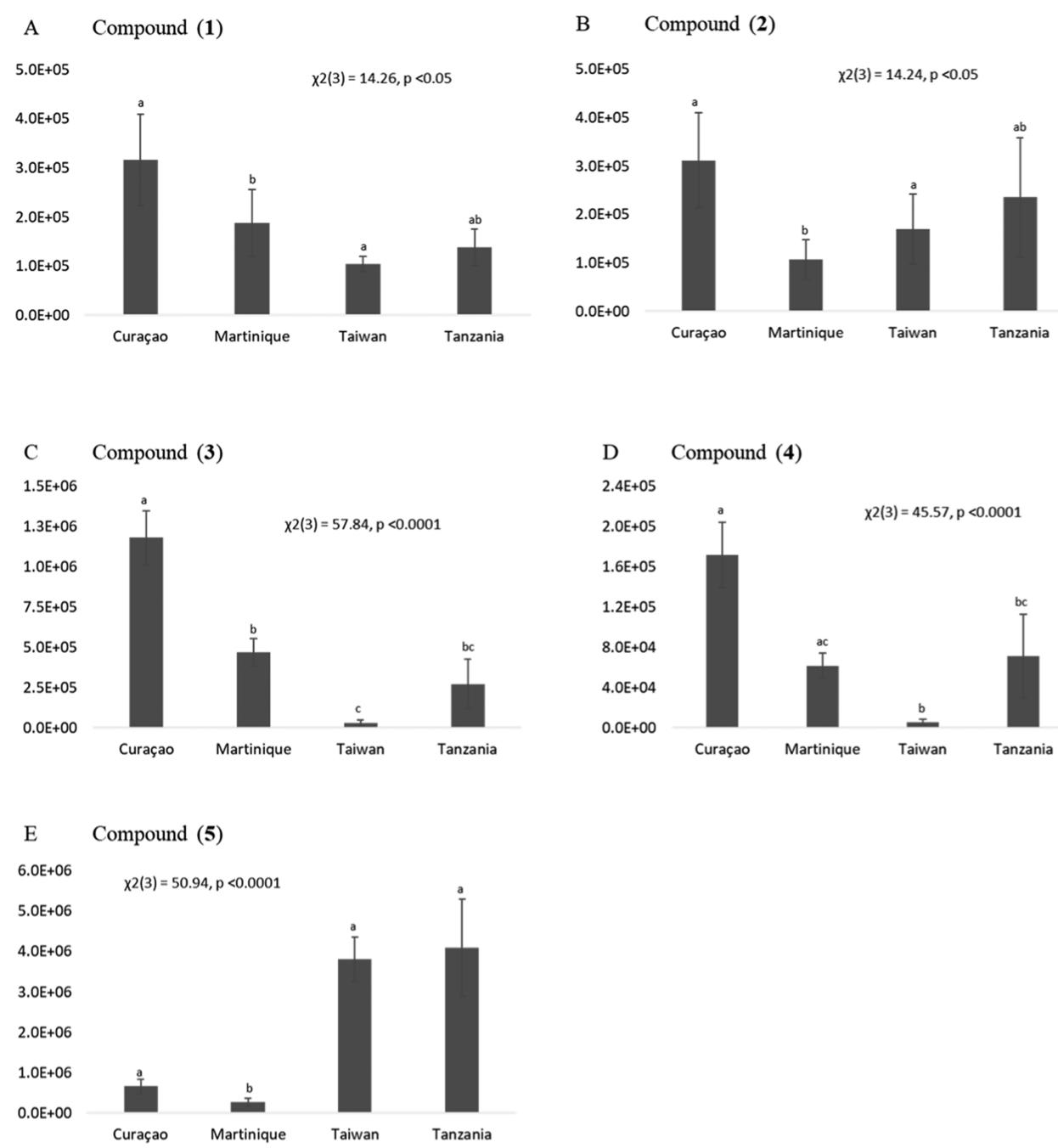

Figure 7. Intensity of the buckets of the most intense peak of the mass spectra for compounds $\mathbf{1 - 5}$ in each location. Error bars indicate the standard error. Results of a Kruskal-Wallis test are shown in each graph. Different letters indicate significant differences in the post-hoc test.

spectrometer (Bruker, Karlsruhe, Germany), operating at the ${ }^{1} \mathrm{H}$ NMR frequency of $600.13 \mathrm{MHz}$, and equipped with a TCI cryoprobe and a $Z$ gradient system. For internal locking, $\mathrm{CH}_{3} \mathrm{OH}-d_{4}$ was used. A presaturation sequence was used to suppress the residual water signal, using low-power selective irradiation at the $\mathrm{H}_{2} \mathrm{O}$ frequency during the recycle delay.

The resulting spectra were phased, baseline corrected and calibrated to HMDSO at $0.07 \mathrm{ppm}$ using TOPSPIN V. 3.0 (Bruker, Karlsruhe, Germany). The NMR spectra were bucketed using AMIX 3.9.12 (Bruker BioSpin GmbH, Rheinstetten, Germany). Bucket data was obtained by spectra integration at $0.04 \mathrm{ppm}$ intervals from 0.20 to $10.02 \mathrm{ppm}$. The peak intensity of individual peaks was scaled to the total intensity of the buckets. The regions between 3.32 and 3.28, 4.9 and 4.8, 3.62 and 3.57, and 1.15 and 1.19 ppm were excluded from the analysis because they correspond to solvent residual signals.

LC-MS Analysis and Data Processing. The methanol fractions obtained from the SPE were dried, and $1 \mathrm{mg}$ was dissolved in $\mathrm{ACN} / \mathrm{H}_{2} \mathrm{O}$ 1:1 to obtain solutions with a final concentration of $1 \mathrm{mg} / \mathrm{mL}$. The fractions were analyzed using a UHPLC-DAD-MS, Thermo Scientific (Dreieich, Germany) UltiMate 3000 system coupled to a Bruker (Bremen, Germany) OTOF-Q II spectrometer with electrospray ionization (ESI). The UHPLC separation was performed on a Phenomenex (Utrecht, The Netherlands), Kinetex, C18 (2.1 $\mathrm{mm} \times 150 \mathrm{~mm}, 2.6 \mu \mathrm{m})$, using a two-step gradient of $0.1 \%$ formic acid in $\mathrm{H}_{2} \mathrm{O}$ (A) and $0.1 \%$ formic acid in $\mathrm{ACN}$ (B), starting at $45 \% \mathrm{~B}$ to $60 \%$ for $15 \mathrm{~min}, 60-90 \%$ for $12.5 \mathrm{~min}$, and $90-98 \% \mathrm{~B}$ for $2.5 \mathrm{~min}$. The flow rate was $0.300 \mathrm{~mL} / \mathrm{min}$, and the column temperature was maintained at $40{ }^{\circ} \mathrm{C}$. The injection volume was set at $1 \mu \mathrm{L}$. The mass spectrometer parameters were set as follows: nebulizer gas 2.0 bar, drying gas $10.0 \mathrm{~mL} / \mathrm{min}$, temperature $250^{\circ} \mathrm{C}$, and capillary voltage 3500 $\mathrm{V}$. The mass spectrometer was operated in positive mode with a scan range of $100-1650 \mathrm{~m} / z$ and sodium formate was used as a calibrant.

The resulting chromatogram was processed to obtain a matrix for further analysis using Brucker Daltonics Profile Analysis (version 2.1, Bremen, Germany). The spectra were divided into buckets of 1 min between 1 and 30 min and $1 \mathrm{~m} / \mathrm{z}$ between 100 and $1450 \mathrm{~m} / z$. The buckets were organized in a matrix, and the data was filtered to remove those buckets that presented a \%CV above $20 \%$ in the quality control samples.

Statistical Analysis. The matrixes obtained from the NMR and LC-MS were used to perform multivariate data analysis using SIMCA-P software (version 15.0.2, Umetrics, Umeå, Sweden). Principal component analysis, PCA, discriminant 
analysis of partial least-squares, PLS-DA, and orthogonal partial least-squares, OPLS-DA, were performed. For the analysis, data was scaled using united variance scaling (NMR) and pareto scaling (LC-MS), and the models were tested using a permutation test and a cross-validation ANOVA (CVANOVA) test. The model was considered valid if CV-ANOVA showed $p<0.05$. For the prediction power of the model, $Q^{2}$ values above 0.4 were required; otherwise, the model was considered valid but with no prediction power.

A heat map was created using a data matrix with the top 40 signals of the VIP plot. This matrix was uploaded on the MetaboanalystR 2.0 Web site (http://www.metaboanalyst. ca). ${ }^{55}$ The dendrogram was obtained by hierarchical cluster analysis using the Euclidean distance and the "Ward" algorithm.

To test if the concentration of each compound differed among locations, the intensity of buckets corresponding to the most intense ion observed in its mass spectra was used. Data was analyzed with IBM SPSS Statistics version 22 (Armonk, NY) using a Kruskal-Wallis Test. Location was used as a factor, and the number of samples was 139. For the compounds that appeared to be significantly different between locations, a post-hoc test was done, and the $P$ values were Bonferroni-corrected.

Isolation and Elucidation. For the isolation of active compounds, extracts of samples from Martinique, Curaçao, and Taiwan were prepared as mentioned in the Sample Collection and Extraction in Experimental Section. The crude extracts were fractionated using an SPE $20 \mathrm{~mL}$ LC-18 Supelco Supelclean (Merck, Darmstadt, Germany) cartridge and eluted using two different methods according to the sample location. The sample from Martinique $(1.0 \mathrm{~g}$ ) was eluted with $100 \mathrm{~mL}$ of $\mathrm{H}_{2} \mathrm{O}, \mathrm{MeOH}$, and $\mathrm{MeOH} / \mathrm{DCM}$ (1:1), yielding three fractions: FM1, FM2, and FM3, respectively. The samples from Curaçao $(1.9 \mathrm{~g})$ and Taiwan $(2.5 \mathrm{~g})$ were eluted using 50 $\mathrm{mL}$ of each of the following solvents: $100 \% \mathrm{H}_{2} \mathrm{O} ; \mathrm{H}_{2} \mathrm{O} / \mathrm{MeOH}$ 8:2, $\mathrm{H}_{2} \mathrm{O} / \mathrm{MeOH}$ 6:4, $\mathrm{H}_{2} \mathrm{O} / \mathrm{MeOH}$ 4:6, $\mathrm{H}_{2} \mathrm{O} / \mathrm{MeOH}$ 2:8, $100 \% \mathrm{MeOH}$, and $\mathrm{MeOH} / \mathrm{DCM} 1: 1$. This resulted in seven fractions of each extract $\mathrm{FC} 1-\mathrm{FC} 7$ for Curaçao samples and FT1-FT7 for Taiwan samples, respectively.

Fraction FM2 (212 mg) was submitted to a size-based separation. The fraction was resuspended in $10 \mathrm{~mL}$ of $\mathrm{MeOH}$ and injected into a Sepacore Flash System (Büchi, HendrikIdo-Ambacht, The Netherlands) with a Sephadex LH-20 (Merck KGaA, Darmstadt, Germany) column and a sample loop of $20 \mathrm{~mL}$. Samples were eluted at a flow rate of $2.5 \mathrm{~mL} /$ min with $\mathrm{MeOH}$. Fractions were collected automatically every minute and combined into nine FM2.1-FM2.9 fractions based on their TLC profiles. The purification of fractions FM2.7, FM2.9, FC4, and FT4 was performed using an Agilent (Santa Clara, CA) 1200 series system on a Phenomenex (Utrecht, The Netherlands) Luna $5 \mu \mathrm{m}, \mathrm{C}-18,250 \mathrm{~mm} \times 10 \mathrm{~mm}$ column and eluted at a flow rate of $3.50 \mathrm{~mL} / \mathrm{min}$ with different gradients of $0.1 \%$ formic acid in $\mathrm{H}_{2} \mathrm{O}(\mathrm{A})$ and $0.1 \%$ formic acid in $\mathrm{MeOH}$ (B). Fractions FM2.7-FM2.9 (49.87 mg) were eluted with a gradient of $75-80 \%$ B for $25 \mathrm{~min}, 80 \%$ B for 15 $\min , 80-100 \%$ B for $2 \mathrm{~min}$, and $100 \% \mathrm{~B}$ for $5 \mathrm{~min}$. This yielded $2.26 \mathrm{mg}$ of $\mathbf{1}$ and $1.58 \mathrm{mg}$ of $\mathbf{2}$. Fraction FC4 (70.6 $\mathrm{mg}$ ) was eluted using the following gradient: $72-85 \%$ B for 52 min, $85-100 \%$ B for $2 \mathrm{~min}$, and $100 \% \mathrm{~B}$ for $10 \mathrm{~min}$. This allowed the isolation of $3(7.16 \mathrm{mg})$ and $4(2.14 \mathrm{mg})$. Fraction FT5 $(94.08 \mathrm{mg}$ ) was eluted using the following gradient: $72-$ $80 \%$ B for $34 \mathrm{~min}, 80-85 \%$ B for $16 \mathrm{~min}, 85-100 \%$ B for 3 min, and $100 \% \mathrm{~B}$ for $3 \mathrm{~min}$. This led to compounds 5 (1.51 $\mathrm{mg})$ and $1(1.00 \mathrm{mg})$.

(9E, 17E)-18-Bromooctadeca-9,17-dien-5,7,15-triynoic Acid (1). White amorphous powder; ${ }^{1} \mathrm{H} \mathrm{NMR}\left(\mathrm{CH}_{3} \mathrm{OH}-d_{4}\right.$, $600 \mathrm{MHz}) \delta_{\mathrm{H}} 1.52 \mathrm{~m}, 1.82$ quint $(J=7.3 \mathrm{~Hz}), 2.18 \mathrm{~m}, 2.29 \mathrm{~m}$, $2.31 \mathrm{~m}, 2.38 \mathrm{t}(J=7.0 \mathrm{~Hz}), 5.55 \mathrm{dm}(J=15.9 \mathrm{~Hz}), 6.23 \mathrm{~m}$, $6.27 \mathrm{~m}, 6.70 \mathrm{~d}(J=14.0 \mathrm{~Hz}) \cdot{ }^{13} \mathrm{C} \mathrm{NMR}\left(\mathrm{CH}_{3} \mathrm{OH}-d_{4}, 150\right.$ $\mathrm{MHz}) \delta_{\mathrm{c}} 19.5,19.6,25.8,28.6,28.6,33.2,36.9,65.9,73.3$, 73.9, 80.2, 83.3, 92.8, 109.8, 117.7, 118.9 and 148.3. HRESIMS $m / z[\mathrm{M}+\mathrm{H}]^{+} 347.0646$ and 349.0631 (calcd for $\mathrm{C}_{18} \mathrm{H}_{20} \mathrm{BrO}_{2}^{+}, 347.0647$ and 349.0626).

Xestospongic Acid (2). White amorphous powder; ${ }^{1} \mathrm{H}$ $\mathrm{NMR}\left(\mathrm{CH}_{3} \mathrm{OH}-d_{4}, 600 \mathrm{MHz}\right) \delta_{\mathrm{H}} 1.43 \mathrm{~m}, 1.49 \mathrm{~m}, 1.51 \mathrm{~m}, 1.63$ quint $(J=7.5 \mathrm{~Hz}), 2.09 \mathrm{~m}, 2.24 \mathrm{~m}, 2.26 \mathrm{~m}, 2.28 \mathrm{~m}, 5.45 \mathrm{dm}(J$ $=15.8 \mathrm{~Hz}), 5.96 \mathrm{dt}(J=15.8,7.2 \mathrm{~Hz}), 6.22 \mathrm{dt}(J=14.0,2.3$ $\mathrm{Hz}), 6.68 \mathrm{~d}(J=14.0 \mathrm{~Hz}) .{ }^{13} \mathrm{C}$ NMR $\left(\mathrm{CH}_{3} \mathrm{OH}-d_{4}, 150 \mathrm{MHz}\right)$ $\delta_{\mathrm{C}} 19.8 \times 2,26.3,28.9,29.2,29.7,29.8,33.3,36.6,78.3,80.2$, 89.2, 93.6, 111.6, 117.9, 119.2, and 143.3. HRESIMS $m / z[M$ $+\mathrm{H}]^{+} 351.0956$ and 353.0939 (calcd for $\mathrm{C}_{18} \mathrm{H}_{24} \mathrm{BrO}_{2}^{+}$, 351.0960 and 353.0939).

(7E, 13E, 15Z)-14,16-Dibromohexadeca-7,13,15-trien-5ynoic Acid (3). White amorphous powder; ${ }^{1} \mathrm{H}$ NMR $\left(\mathrm{CH}_{3} \mathrm{OH}-d_{4}, 600 \mathrm{MHz}\right) \delta_{\mathrm{H}}, 1.40 \mathrm{~m}, 1.44 \mathrm{~m}, 1.78$ quint $(J=$ $7.2 \mathrm{~Hz}), 2.04 \mathrm{~m}, 2.08 \mathrm{~m}, 2.34 \mathrm{dt}(J=2.0,7.0 \mathrm{~Hz}), 2.40 \mathrm{t}(J=$ $7.4 \mathrm{~Hz}), 5.45 \mathrm{dm}(J=15.8 \mathrm{~Hz}), 5.99 \mathrm{dt}(J=15.8,7.1 \mathrm{~Hz}), 6.07$ $\operatorname{td}(J=7.7,1.5 \mathrm{~Hz}), 6.55 \mathrm{~d}(J=7.6 \mathrm{~Hz}), 6.78 \mathrm{dm}(J=7.6 \mathrm{~Hz})$. ${ }^{13} \mathrm{C}$ NMR $\left(\mathrm{CH}_{3} \mathrm{OH}-d_{4}, 150 \mathrm{MHz}\right) \delta_{\mathrm{c}} 19.4,25.4,29.1,29.5$, 32.0, 33.6, 33.9, 80.8, 88.1, 111.3, 113.4, 114.8, 132.3, 137.4, 143.9 and 177.3. HRESIMS $m / z[\mathrm{M}+\mathrm{H}]^{+}$402.9904, 404.9884, 406.9867 (calcd for $\mathrm{C}_{16} \mathrm{H}_{21} \mathrm{Br}_{2} \mathrm{O}_{2}^{+}, 402.9903$, 404.9883, 406.9862) and $[\mathrm{M}+\mathrm{Na}]^{+}$424.9727, 426.9706, 428.9685 (calcd for $\mathrm{C}_{16} \mathrm{H}_{20} \mathrm{Br}_{2} \mathrm{NaO}_{2}^{+}, 424.9723$, 426.9702, 428.9682).

Compound 4. White amorphous powder; ${ }^{1} \mathrm{H}$ NMR $\left(\mathrm{CH}_{3} \mathrm{OH}-d_{4}, 600 \mathrm{MHz}\right) \delta_{\mathrm{H}}$ in Table $1 .{ }^{13} \mathrm{C} \mathrm{NMR}\left(\mathrm{CH}_{3} \mathrm{OH}-\right.$ $\left.d_{4}, 150 \mathrm{MHz}\right) \delta_{\mathrm{C}}$ in Table 1 . HRESIMS $m / z[\mathrm{M}+\mathrm{H}]^{+}$ 639.0777, 641.0761, 643.0749 (calcd for $\mathrm{C}_{25} \mathrm{H}_{37} \mathrm{Br}_{2} \mathrm{O}_{9}{ }^{+}$, 639.0804, 641.0784, 643.0763) and, $[\mathrm{M}+\mathrm{Na}]^{+}$661.0580, 663.0581, 665.0563 (calcd for $\mathrm{C}_{25} \mathrm{H}_{36} \mathrm{Br}_{2} \mathrm{NaO}_{9}^{+}, 661.0624$, $663.0603,665.0583)$

Compound 5. White amorphous powder; ${ }^{1} \mathrm{H}$ NMR $\left(\mathrm{CH}_{3} \mathrm{OH}-d_{4}, 600 \mathrm{MHz}\right) \delta_{\mathrm{H}}$ in Table $1 .{ }^{13} \mathrm{C} \mathrm{NMR}\left(\mathrm{CH}_{3} \mathrm{OH}-\right.$ $\left.d_{4}, 150 \mathrm{MHz}\right) \delta_{\mathrm{C}}$ in Table 1 . HRESIMS $m / z[\mathrm{M}+\mathrm{H}]^{+}$ 588.1718, 590.1702 (calcd for $\mathrm{C}_{26} \mathrm{H}_{40} \mathrm{BrNO}_{7} \mathrm{P}^{+} m / z$ 588.1726, $590.1705)$

Antibacterial Activity Test. Bacterial Strains. The strains used in this study were the Gram-positive bacteria $S$. aureus (CECT976) and Gram-negative bacteria E. coli (DH5 $\alpha$, Promega). The strains had been kept at $-80{ }^{\circ} \mathrm{C}$ (in $100 \%$ glycerol). For their use, the strains were transferred onto Mueller-Hinton agar plates (MHA) (Sigma-Aldrich, Zwijndrecht, The Netherlands) and incubated overnight at $37^{\circ} \mathrm{C}$.

Antimicrobial Testing by the Microdilution Method. A broth microdilution method was used to determine the minimum inhibitory concentration (MIC) according to the CLSI (Clinical Laboratory Standards Institute) guidelines using 96-well microtiter plates. The MIC is defined as the lowest concentration of each extract, which completely inhibits bacterial growth. For antimicrobial testing, the extracts were dissolved in $100 \%$ dimethyl sulfoxide (DMSO) in a concentration of $10 \mathrm{mg} / \mathrm{mL}$. All experiments were performed in triplicate. Ninety microliters of Mueller-Hinton broth (MHB) and $10 \mu \mathrm{L}$ of the tested extract were added into the 
first well. Then, 2-fold serial dilutions of the extracts were prepared by dilution with MHB to achieve a decreasing range of concentrations from 512 to $516 \mu \mathrm{g} / \mathrm{mL}$ in the microtiter plates. The highest concentration of DMSO after dilution was $<5 \%$, to avoid affecting the growth of the bacterial strains. From the overnight cultures of the bacterial strains, a single colony was used to inoculate the $\mathrm{MHB}$ at $37^{\circ} \mathrm{C}$ with agitation $(150 \mathrm{rpm})$. The cultures were then further diluted in MHB and adjusted to a turbidity level of $0.5 \mathrm{McF}$ arland standard solution (approximately $10^{6} \mathrm{CFU} / \mathrm{mL}$ ). Each well was then inoculated with $50 \mu \mathrm{L}$ of the bacterial solution at a density of $10^{6} \mathrm{CFU} /$ $\mathrm{mL}$. Spectinomycin (100 mg/mL) (Sigma-Aldrich, Zwijndrecht, The Netherlands) was used as a positive control and $5 \%$ DMSO as a negative control. The inoculated microtiter plates were incubated at $30{ }^{\circ} \mathrm{C}$ for $24 \mathrm{~h}$. Bacterial growth was detected by optical density.

\section{ASSOCIATED CONTENT}

\section{SI Supporting Information}

The Supporting Information is available free of charge at https://pubs.acs.org/doi/10.1021/acsomega.0c01151.

Sample collection information; example ${ }^{1} \mathrm{H}$ NMR and LC-MS profiles of Xestospongia samples collected in four locations; and spectroscopic and spectrometric data of the isolated compounds (PDF)

\section{AUTHOR INFORMATION}

\section{Corresponding Author}

Young Hae Choi - Natural Products Laboratory, Institute of Biology, Leiden University, 2333 BE Leiden, The Netherlands; College of Pharmacy, Kyung Hee University, 02447 Seoul, Republic of Korea; (1) orcid.org/0000-0003-1484-1700; Phone: +31-(0)71-527-4528; Email: y.choi@ chem.leidenuniv.nl; Fax: +31-(0)71-527-4511

\section{Authors}

Lina M. Bayona - Natural Products Laboratory, Institute of Biology, Leiden University, 2333 BE Leiden, The Netherlands

Gemma van Leeuwen - Natural Products Laboratory, Institute of Biology, Leiden University, 2333 BE Leiden, The Netherlands

Özlem Erol - Natural Products Laboratory, Institute of Biology, Leiden University, 2333 BE Leiden, The Netherlands

Thomas Swierts - Naturalis Biodiversity Center, Marine Biodiversity, 2333 CR Leiden, The Netherlands; Institute of Environmental Sciences, Leiden University, 2333 CC Leiden, The Netherlands

Esther van der Ent - Naturalis Biodiversity Center, Marine Biodiversity, 2333 CR Leiden, The Netherlands; Institute of Environmental Sciences, Leiden University, 2333 CC Leiden, The Netherlands

Nicole J. de Voogd - Naturalis Biodiversity Center, Marine Biodiversity, 2333 CR Leiden, The Netherlands; Institute of Environmental Sciences, Leiden University, 2333 CC Leiden, The Netherlands

Complete contact information is available at:

https://pubs.acs.org/10.1021/acsomega.0c01151

\section{Author Contributions}

Design of the study, L.M.B., N.J.d.V., and Y.H.C.; fieldwork collection and sample pretreatment, T.S., E.v.d.E., and N.J.d.V.; extraction and purifications of compounds, L.M.B. and G.v.L.; data analysis, L.M.B. and Y.H.C.; activity test, O.E., compounds' elucidation, L.M.B. and Y.H.C.; writing of the original manuscript, L.M.B; led the writing of the manuscript, L.M.B. and Y.H.C.; and supervision, N.J.d.V. and Y.H.C. All authors have read and agreed to the published version of the manuscript.

\section{Funding}

This work was supported by COLCIENCIAS (\#728, Science Technology and Innovation Ministry, Colombian Government) and NWO-VIDI (\#16.161.301) and NWO-Aspasia (\#105-010.030).

\section{Notes}

The authors declare no competing financial interest.

\section{ACKNOWLEDGMENTS}

The authors greatly appreciate the contribution of Dr. Erika G. Wilson in the scientific discussion of this paper. The specimens from Martinique were collected during the Madibenthos expeditions (PI Philippe Bouchet) organized by the Museum National d'Histoire Naturelle (MNHN) and the Marine Protected Areas Agency (AAMP), the Regional Directorate for the Environment (DEAL), and the Martinique Water Bureau (ODE) with funding from the European Regional Development Fund (ERDF), the Territorial Collectivity of Martinique (CTM), and Saint-James Plantations and BRED Banque populaire. Yusheng Huang of the National Penghu University of Science and Technology, Penghu, Taiwan, and Christian Vaterlaus of Marine Cultures, Jambiana Tanzania, are thanked for their assistance in the field.

\section{REFERENCES}

(1) Blunt, J. W.; Carroll, A. R.; Copp, B. R.; Davis, R. A.; Keyzers, R. A.; Prinsep, M. R. Marine Natural Products. Nat. Prod. Rep. 2018, 35, $8-53$.

(2) Gerwick, W.; Moore, B. Lessons from the Past and Charting the Future of Marine Natural Products Drug Discovery and Chemical Biology. Chem. Biol. 2012, 19, 85-98.

(3) Newman, D. J.; Cragg, G. M. Advanced Preclinical and Clinical Trials of Natural Products and Related Compounds from Marine Sources. Curr. Med. Chem. 2004, 11, 1693-1713.

(4) Altmann, K.-H. Drugs from the Oceans: Marine Natural Products as Leads for Drug Discovery. CHIMIA Int. J. Chem. 2017, $71,646-652$.

(5) Blunt, J. W.; Copp, B. R.; Keyzers, R. A.; Munro, M. H. G.; Prinsep, M. R. Marine Natural Products. Nat. Prod. Rep. 2016, 33, 382-431.

(6) Blunt, J. W.; Copp, B. R.; Keyzers, R. A.; Munro, M. H. G.; Prinsep, M. R. Marine Natural Products. Nat. Prod. Rep. 2017, 34, 235-294.

(7) Belarbi, E.; Gómez, A. C.; Chisti, Y.; Camacho, F. G.; Grima, E. M. Producing Drugs from Marine Sponges. Biotechnol. Adv. 2003, 21, 585-598.

(8) Gupta, S. K. Drug Discovery and Clinical Research; Jaypee Brothers Medical Publishers, 2011.

(9) Viant, M. R. Metabolomics of Aquatic Organisms. Mar. Ecol.: Prog. Ser. 2007, 332, 301-306.

(10) Pomponi, S. A. The Bioprocess-Technological Potential of the Sea. J. Biotechnol. 1999, 70, 5-13.

(11) Cuevas, C.; Francesch, A. Development of Yondelis (Trabectedin, ET-743). A Semisynthetic Process Solves the Supply Problem. Nat. Prod. Rep. 2009, 26, 322-337.

(12) Santiago, V. S.; Manzano, G. G.; Yu, C. C.; Aliño, P. M.; Salvador-Reyes, L. A. Mariculture Potential of RenieramycinProducing Philippine Blue Sponge Xestospongia Sp. (Porifera: Haplosclerida). Aquaculture 2019, 502, 356-364. 
(13) Ruiz, C.; Valderrama, K.; Zea, S.; Castellanos, L. Mariculture and Natural Production of the Antitumoural (+)-Discodermolide by the Caribbean Marine Sponge Discodermia Dissoluta. Mar. Biotechnol. 2013, 15, 571-583.

(14) de Voogd, N. J. The Mariculture Potential of the Indonesian Reef-Dwelling Sponge Callyspongia (Euplacella) Biru: Growth, Survival and Bioactive Compounds. Aquaculture 2007, 262, 54-64.

(15) Page, M. J.; Northcote, P. T.; Webb, V. L.; Mackey, S.; Handley, S. J. Aquaculture Trials for the Production of Biologically Active Metabolites in the New Zealand Sponge Mycale Hentscheli (Demospongiae: Poecilosclerida). Aquaculture 2005, 250, 256-269.

(16) Hadas, E.; Shpigel, M.; Ilan, M. Sea Ranching of the Marine Sponge Negombata Magnifica (Demospongiae, Latrunculiidae) as a First Step for Latrunculin B Mass Production. Aquaculture 2005, 244, $159-169$.

(17) Kim, H. K.; Choi, Y. H.; Verpoorte, R. NMR-Based Metabolomic Analysis of Plants. Nat. Protoc. 2010, 5, 536-549.

(18) Mehbub, F. M.; Lei, J.; Franco, C.; Zhang, W. Marine Sponge Derived Natural Products between 2001 and 2010: Trends and Opportunities for Discovery of Bioactives. Mar. Drugs 2014, 12, $4539-4577$.

(19) Fiore, C. L.; Baker, D. M.; Lesser, M. P. Nitrogen Biogeochemistry in the Caribbean Sponge, Xestospongia Muta: A Source or Sink of Dissolved Inorganic Nitrogen? PLoS One 2013, 8, No. e72961.

(20) Zhou, X.; Xu, T.; Yang, X.-W.; Huang, R.; Yang, B.; Tang, L.; Liu, Y. Chemical and Biological Aspects of Marine Sponges of the Genus Xestospongia. Chem. Biodiversity 2010, 7, 2201-2227.

(21) Diaz, M. C.; Rützler, K. Sponges: An Essential Component of Caribbean Coral Reefs. Bull. Mar. Sci. 2001, 62, 535-546.

(22) Swierts, T.; Cleary, D. F. R.; de Voogd, N. J. Prokaryotic Communities of Indo-Pacific Giant Barrel Sponges Are More Strongly Influenced by Geography than Host Phylogeny. FEMS Microbiol. Ecol. 2018, 94, No. fiy194.

(23) McMurray, S. E.; Blum, J. E.; Pawlik, J. R. Redwood of the Reef: Growth and Age of the Giant Barrel Sponge Xestospongia Muta in the Florida Keys. Mar. Biol. 2008, 155, 159-171.

(24) Zea, S. Cover of Sponges and Other Sessile Organisms in Rocky and Coral Reef Habitats of Santa Marta, Colombian Caribbean Sea. Caribb. J. Sci. 1993, 29, 75-88.

(25) Setiawan, E.; de Voogd, N. J.; Swierts, T.; Hooper, J. N. A.; Wörheide, G.; Erpenbeck, D. MtDNA Diversity of the Indonesian Giant Barrel Sponge Xestospongia Testudinaria (Porifera: Haplosclerida) - Implications from Partial Cytochrome Oxidase 1 Sequences. J. Mar. Biol. Assoc. U.K. 2016, 96, 323-332.

(26) Swierts, T.; Peijnenburg, K. T. C. A.; de Leeuw, C. A.; Breeuwer, J. A. J.; Cleary, D. F. R.; de Voogd, N. J. Globally Intertwined Evolutionary History of Giant Barrel Sponges. Coral Reefs 2017, 36, 933-945.

(27) Swierts, T.; Peijnenburg, K. T. C. A.; de Leeuw, C.; Cleary, D. F. R.; Hörnlein, C.; Setiawan, E.; Wörheide, G.; Erpenbeck, D.; de Voogd, N. J. Lock, Stock and Two Different Barrels: Comparing the Genetic Composition of Morphotypes of the Indo-Pacific Sponge Xestospongia Testudinaria. PLoS One 2013, 8, No. e74396.

(28) Page, M.; West, L.; Northcote, P.; Battershill, C.; Kelly, M. Spatial and Temporal Variability of Cytotoxic Metabolites in Populations of the New Zealand Sponge Mycale Hentscheli. J. Chem. Ecol. 2005, 31, 1161-1174.

(29) Sacristan-Soriano, O.; Banaigs, B.; Becerro, M. A. Relevant Spatial Scales of Chemical Variation in Aplysina Aerophoba. Mar. Drugs 2011, 9, 2499-2413.

(30) Rohde, S.; Gochfeld, D. J.; Ankisetty, S.; Avula, B.; Schupp, P. J.; Slattery, M. Spatial Variability in Secondary Metabolites of the Indo-Pacific Sponge Stylissa Massa. J. Chem. Ecol. 2012, 38, 463-475.

(31) Reverter, M.; Tribalat, M.-A.; Pérez, T.; Thomas, O. P. Metabolome Variability for Two Mediterranean Sponge Species of the Genus Haliclona: Specificity, Time, and Space. Metabolomics 2018, 14, 114.
(32) Zheng, X.; Su, M.; Pei, L.; Zhang, T.; Ma, X.; Qiu, Y.; Xia, H.; Wang, F.; Zheng, X.; Gu, X.; Song, X.; Li, X.; Qi, X.; Chen, G.; Bao, Y.; Chen, T.; Chi, Y.; Zhao, A.; Jia, W. Metabolic Signature of Pregnant Women with Neural Tube Defects in Offspring. J. Proteome Res. 2011, 10, 4845-4854.

(33) Cai, H.-L.; Li, H.-D.; Yan, X.-Z.; Sun, B.; Zhang, Q.; Yan, M.; Zhang, W.-Y.; Jiang, P.; Zhu, R.-H.; Liu, Y.-P.; Fang, P.-F.; Xu, P.; Yuan, H.-Y.; Zhang, X.-H.; Hu, L.; Yang, W.; Ye, H.-S. Metabolomic Analysis of Biochemical Changes in the Plasma and Urine of FirstEpisode Neuroleptic-Naive Schizophrenia Patients after Treatment with Risperidone. J. Proteome Res. 2012, 11, 4338-4350.

(34) Gauvin, A.; Smadja, J.; Aknin, M.; Gaydou, E. M. Sterol Composition and Chemotaxonomic Considerations in Relation to Sponges of the Genus Xestospongia. Biochem. Syst. Ecol. 2004, 32, 469-476.

(35) Kerr, R. G.; Kerr, S. L.; Pettit, G. R.; Herald, D. L.; Groy, T. L.; Djerassi, C. Sterols of Marine Invertebrates. 63. Isolation and Structure Elucidation of Sutinasterol, the Major Sterol of the Marine Sponge Xestospongia Sp. J. Org. Chem. 1991, 56, 58-62.

(36) Pham, N. B.; Butler, M. S.; Hooper, J. N. A.; Moni, R. W.; Quinn, R. J. Isolation of Xestosterol Esters of Brominated Acetylenic Fatty Acids from the Marine Sponge Xestospongia Testudinaria. J. Nat. Prod. 1999, 62, 1439-1442.

(37) Roll, D. M.; Scheuer, P. J.; Matsumoto, G. K.; Clardy, J. Halenaquinone, a Pentacyclic Polyketide from a Marine Sponge. J. Am. Chem. Soc. 1983, 105, 6177-6178.

(38) Calcul, L.; Longeon, A.; Mourabit, A. A.; Guyot, M.; BourguetKondracki, M.-L. Novel Alkaloids of the Aaptamine Class from an Indonesian Marine Sponge of the Genus Xestospongia. Tetrahedron 2003, 59, 6539-6544.

(39) Kobayashi, M.; Chen, Y.-J.; Aoki, S.; In, Y.; Ishida, T.; Kitagawa, I. Four New $\beta$-Carboline Alkaloids Isolated from Two Okinawan Marine Sponges of Xestospongia Sp. and Haliclona Sp.). Tetrahedron 1995, 51, 3727-3736.

(40) Jiang, W.; Liu, D.; Deng, Z.; de Voogd, N. J.; Proksch, P.; Lin, W. Brominated Polyunsaturated Lipids and Their Stereochemistry from the Chinese Marine Sponge Xestospongia Testudinaria. Tetrahedron 2011, 67, 58-68.

(41) Liu, D.; Xu, J.; Jiang, W.; Deng, Z.; de Voogd, N. J.; Proksch, P.; Lin, W. Xestospongienols A-L, Brominated Acetylenic Acids from the Chinese Marine Sponge Xestospongia Testudinaria. Helv. Chim. Acta 2011, 94, 1600-1607.

(42) Morinaka, B. I.; Skepper, C. K.; Molinski, T. F. Ene-Yne Tetrahydrofurans from the Sponge Xestospongia Muta. Exploiting a Weak CD Effect for Assignment of Configuration. Org. Lett. 2007, 9, $1975-1978$.

(43) He, F.; Mai, L. H.; Longeon, A.; Copp, B. R.; Loaëc, N.; Bescond, A.; Meijer, L.; Bourguet-Kondracki, M.-L. Novel Adociaquinone Derivatives from the Indonesian Sponge Xestospongia Sp. Mar. Drugs 2015, 13, 2617-2628.

(44) Bourguet-Kondracki, M. L.; Rakotoarisoa, M. T.; Martin, M. T.; Guyot, M. Bioactive Bromopolyacetylenes from the Marine Sponge Xestospongia Testudinaria. Tetrahedron Lett. 1992, 33, 225-226.

(45) Fiore, C. L.; Jarett, J. K.; Lesser, M. P. Symbiotic Prokaryotic Communities from Different Populations of the Giant Barrel Sponge, Xestospongia Muta. MicrobiologyOpen 2013, 2, 938-952.

(46) Patil, A. D.; Kokke, W. C.; Cochran, S.; Francis, T. A.; Tomszek, T.; Westley, J. W. Brominated Polyacetylenic Acids from the Marine Sponge Xestospongia Muta: Inhibitors of HIV Protease. J. Nat. Prod. 1992, 55, 1170-1177.

(47) Quinn, R. J.; Tucker, D. J. A Brominated Bisacetylenic Acid from the Marine Sponge Xestospongia Testudinaria. Tetrahedron Lett. 1985, 26, 1671-1672.

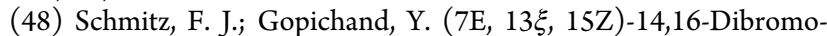
7,13,15-Hexadecatrien-5-Ynoic Acid. A Novel Dibromo Acetylenic Acid from the Marine Sponge Xestospongia Muta. Tetrahedron Lett. 1978, 19, 3637-3640.

(49) Villegas-Plazas, M.; Wos-Oxley, M. L.; Sanchez, J. A.; Pieper, D. H.; Thomas, O. P.; Junca, H. Variations in Microbial Diversity and 
Metabolite Profiles of the Tropical Marine Sponge Xestospongia Muta with Season and Depth. Microb. Ecol. 2019, 78, 243-256.

(50) Wicke, C.; Hüners, M.; Wray, V.; Nimtz, M.; Bilitewski, U.; Lang, S. Production and Structure Elucidation of Glycoglycerolipids from a Marine Sponge-Associated Microbacterium Species. J. Nat. Prod. 2000, 63, 621-626.

(51) Fan, T. W.-M. Metabolite Profiling by One- and TwoDimensional NMR Analysis of Complex Mixtures. Prog. Nucl. Magn. Reson. Spectrosc. 1996, 28, 161-219.

(52) Zhou, Z.-F.; Menna, M.; Cai, Y.-S.; Guo, Y.-W. Polyacetylenes of Marine Origin: Chemistry and Bioactivity. Chem. Rev. 2015, 115, $1543-1596$

(53) Hirsh, S.; Carmely, S.; Kashman, Y. Brominated Unsaturated Acids from the Marine Sponge Xestospongia Sp. Tetrahedron 1987, 43, 3257-3261.

(54) D’Arrigo, P.; Servi, S. Synthesis of Lysophospholipids. Molecules 2010, 15, 1354-1377.

(55) Chong, J.; Yamamoto, M.; Xia, J. MetaboAnalystR 2.0: From Raw Spectra to Biological Insights. Metabolites 2019, 9, 57. 